differences may not be so clear-cut in the clinical setting and there are significant overlaps in clinical, physiological and pathological features of the two diseases, including the mechanisms of bronchial hyperresponsiveness and atopy that drive obstructive phenotypes [7]. Although asthma may progress to chronic irreversible airflow obstruction, changes in reversibility over time are not widely reported $[8,9]$. It may be that we require a new taxonomy to better define the various disorders of airway obstruction.

So in the end perhaps it all comes back to the title of our paper [1]: COPD prevalence... a matter of definition.

\section{P. Shirtcliffe, M. Weatherall and R. Beasley}

Medical Research Institute of New Zealand, Wellington, New Zealand.

\section{STATEMENT OF INTEREST}

None declared.

\section{REFERENCES}

1 Shirtcliffe P, Weatherall M, Marsh S, et al. COPD prevalence in a random population survey: a matter of definition. Eur Respir J 2007; 30: 232-239.
2 Rabe KF, Hurd S, Anzueto A, et al. Global strategy for the diagnosis, management, and prevention of chronic obstructive pulmonary disease: GOLD executive summary. Am J Respir Crit Care Med 2007; 176: 532-555.

3 Buist AS, McBurnie MA, Vollmer WM, et al. International variation in the prevalence of COPD (the BOLD Study): a population-based prevalence study. Lancet 2007; 370: 741-750.

4 Welcome to GINA the Global Initiative For Asthma. www.ginasthma.com Date last accessed: January 30, 2007.

5 Guerra S. Overlap of asthma and COPD. Curr Opin Pulm Med 2005; 11: 7-13.

6 Sciurba FC. Physiologic similarities and differences between COPD and asthma. Chest 2004; 126: Suppl. 2, 117S-124S.

7 Kraft M. Asthma and chronic obstructive pulmonary disease exhibit common origins in any country! Am J Respir Crit Care Med 2006; 174: 238-244.

8 Vonk JM, Jongepier H, Panhuysen CI, Schouten JP, Bleecker ER, Postma DS. Risk factors associated with the presence of irreversible airflow limitation and reduced transfer coefficient in patients with asthma after 26 years of follow up. Thorax 2003; 58: 322-327.

9 Ulrik CS, Backer V. Nonreversible airflow obstruction in lifelong nonsmokers with moderate to severe asthma. Eur Respir J 1999; 14: 892-896.

\title{
Right ventricular dysfunction and functional limitation in idiopathic pulmonary fibrosis
}

\section{To the Editors:}

We read with great interest the paper by DAL CORSO et al. [1] in a recent issue of the European Respiratory Journal. The authors used a 6-min step test to estimate effort tolerance and exerciserelated oxyhaemoglobin desaturation in patients with interstitial lung disease. Although desaturation with exertion is well accepted as a prognostic tool in patients with interstitial lung disease, conflicting reports exist regarding the distance covered during the test [2-5]. Moreover, evidence is lacking regarding the possible association between cardiac function, exercise capacity and exercise desaturation in patients with interstitial lung disease. In a small cohort of 22 patients (mean \pm SD age $65 \pm 9$ yrs) with well-defined idiopathic pulmonary fibrosis (IPF), we used the 6-min walk test (6MWT) to assess prognosis and to investigate the association of exercise capacity with left and right ventricular echocardiographic parameters. All patients underwent a complete echocardiographic study, including two-dimensional, colour flow, spectral Doppler as well as tissue Doppler imaging for the evaluation of right and left ventricular systolic and diastolic function.

Mean time from initial diagnosis of the disease was 9 months. After a median follow-up period of 22 months, five deaths were recorded (four were due to respiratory failure decompensation and one followed sepsis). A cut-off value of $225 \mathrm{~m}$ for 6MWT distance predicted survival after follow-up with $100 \%$ sensitivity and $60 \%$ specificity (area under curve (AUC) 0.77 , $p=0.01$ ). Moreover, a cut-off value of $>5 \%$ for desaturation with exercise predicted mortality with $58 \%$ sensitivity and $100 \%$ specificity (AUC 0.82, $\mathrm{p}=0.006$ ). Amongst all echocardiographic parameters, 6MWT distance correlated significantly with pulmonary artery systolic pressure $(r=-0.53, p=0.01$; fig. 1$)$, early diastolic peak myocardial velocity of the tricuspid annulus $(\mathrm{r}=-0.45, \mathrm{p}=0.03$; fig. 1$)$ and late diastolic peak myocardial velocity of the tricuspid annulus $(r=-0.44, p=0.03)$. No correlation was found between oxygen desaturation during the $6 \mathrm{MWT}$ and any of the echocardiographic parameters.

Although the number of patients evaluated was small, our results indicate that there is a close association between exercise capacity, indices of right ventricular diastolic function and prognosis in patients with IPF. Exercise capacity in patients with IPF has been shown to be limited mainly by gas exchange and ventilatory impairment [6]. The conflicting reports in the literature regarding the relationship between $6 \mathrm{MWT}$ distance and mortality in IPF patients probably reflect differences in the exercise protocols and, particularly, the time and reason of the 6MWT termination [2-5]. Nevertheless, the 

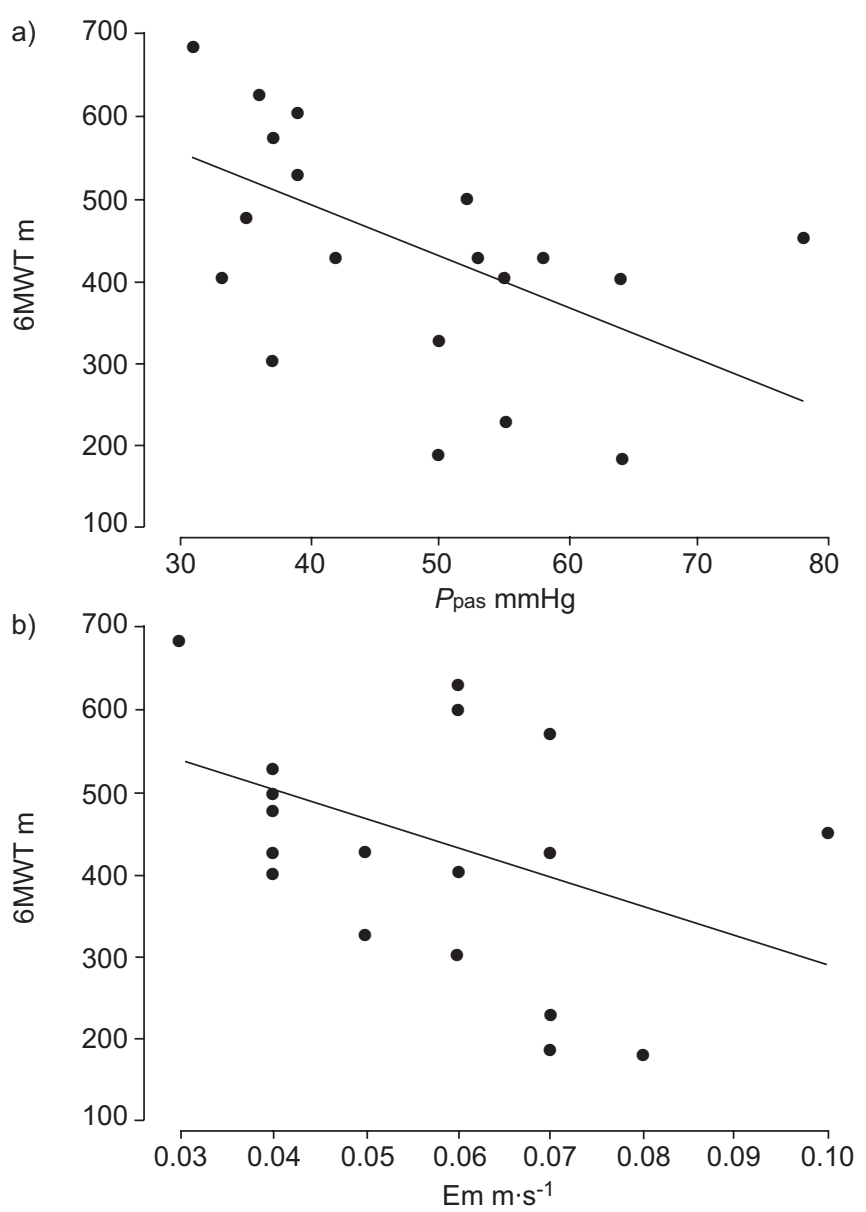

FIGURE 1. Scatter plots showing the relationship between 6-min walk test (6MWT) distance and a) pulmonary artery systolic pressure (Ppas) and b) early diastolic peak myocardial velocity $(\mathrm{Em})$ of the tricuspid annulus.

majority of authors [2-5] agree that the degree of desaturation seems to be a strong predictor of mortality, as we also confirmed in our cohort. Importantly, exercise capacity is not only dependent on respiratory function; cardiac function and muscle function are other important factors that can come into play [7]. Moreover, poor 6MWT performance should raise suspicion of the presence of underlying pulmonary arterial hypertension.

As the prevalence of right ventricular dysfunction is high in patients with end-stage pulmonary disease [8], we believe that the echocardiographic evaluation of right ventricular function can be complementary to clinical evaluation and functional assessment in these patients.

\section{G. Giannakoulas*, T.D. Karamitsos", G. Pitsiou and H.I. Karvounis ${ }^{+}$}

*Congenital Heart Centre and Centre for Pulmonary Hypertension, Royal Brompton Hospital, London, "Dept of Cardiovascular Medicine, University of Oxford, John Radcliffe Hospital, Oxford, UK. "Respiratory Failure Unit, Aristotle University of Thessaloniki, and 'First Cardiology Dept, AHEPA Hospital, Thessaloniki, Greece.

\section{STATEMENT OF INTEREST}

None declared.

\section{REFERENCES}

1 Dal Corso S, Duarte SR, Neder JA, et al. A step test to assess exercise-related oxygen desaturation in interstitial lung disease. Eur Respir J 2007; 29: 330-336.

2 Eaton T, Young P, Milne D, Wells AU. Six-minute walk, maximal exercise tests: reproducibility in fibrotic interstitial pneumonia. Am J Respir Crit Care Med 2005; 171: 1150-1157.

3 Flaherty KR, Andrei AC, Murray S, et al. Idiopathic pulmonary fibrosis: prognostic value of changes in physiology and six-minute-walk test. Am J Respir Crit Care Med 2006; 174: 803-809.

4 Hallstrand TS, Boitano LJ, Johnson WC, Spada CA, Hayes JG, Raghu G. The timed walk test as a measure of severity and survival in idiopathic pulmonary fibrosis. Eur Respir J 2005; 25: 96-103.

5 Lama VN, Flaherty KR, Toews GB, et al. Prognostic value of desaturation during a 6-minute walk test in idiopathic interstitial pneumonia. Am J Respir Crit Care Med 2003; 168: 1084-1090.

6 Harris-Eze AO, Sridhar G, Clemens RE, Zintel TA, Gallagher CG, Marciniuk DD. Role of hypoxemia and pulmonary mechanics in exercise limitation in interstitial lung disease. Am J Respir Crit Care Med 1996; 154: 994-1001.

7 Dimopoulos K, Diller GP, Piepoli MF, Gatzoulis MA. Exercise intolerance in adults with congenital heart disease. Cardiol Clin 2006; 24: 641-660.

8 Vizza CD, Lynch JP, Ochoa LL, Richardson G, Trulock EP. Right and left ventricular dysfunction in patients with severe pulmonary disease. Chest 1998; 113: 576-583.

DOI: $10.1183 / 09031936.00083407$

\section{From the authors:}

We thank G. Giannakoulas and co-workers for their interest in our study [1]. Unfortunately, haemodynamic measurements at rest or during exercise were not performed in our patients with interstitial lung diseases. Therefore, we were unable to evaluate the relationship between exercise tolerance and those physiological adjustments. In line with these results, however, we did find that oxygen pulse, an index of stroke volume in some circumstances [2], was positively related to the number of steps climbed in $6 \mathrm{~min}(\mathrm{r}=0.64 ; \mathrm{p}<0.01)$. Conversely, there was an inverse relationship between oxygen pulse and the nadir of oxyhaemoglobin desaturation at exercise cessation $(\mathrm{r}=-0.57 ; \mathrm{p}<0.01)$.

Additional studies are needed to better characterise the haemodynamic responses to stepping and walking in these patients and their relationships with resting echocardiographic parameters and the severity of chronic hypoxaemia. We have preliminary data (data not published) suggesting that the step test also provides prognostic information in these patients and that it might constitute a more practical test paradigm than walking tests performed in clinical settings. 